\title{
Olhares em formação: refletindo a prática da terapia ocupacional em um contexto cultural a partir de experiências com povos indígenas
}

\author{
Maria Daniela Corrêa de Macedo, Amabile Teresa de Lima Neves, Giovanna Bardi, \\ Gustavo Artur Monzeli, Vinícius Vieira Mota
}

Departamento de Terapia Ocupacional, Universidade Federal do Espírito Santo - UFES, Vitória, ES, Brasil.

\begin{abstract}
Resumo: O presente artigo resulta de um processo de reflexão acerca da temática terapia ocupacional e cultura, através da análise das experiências práticas de um projeto de extensão. Objetivou-se aprofundar os conhecimentos da terapia ocupacional em contextos culturais e as ações técnicas do terapeuta ocupacional neste âmbito, à luz das questões de etnicidade. Trata-se de uma pesquisa documental e qualitativa. O objeto de análise foram os relatos de experiência dos extensionistas e da técnica de terapia ocupacional, coletados por meio dos seus relatórios escritos entre 2012 e 2014. Para análise dos dados, utilizaram-se as categorizações propostas por Bardin. As categorias de análise encontradas dizem respeito às ações técnicas em terapia ocupacional, intituladas ação cultural e ação étnica. Os resultados demonstraram que, nas experiências realizadas junto à comunidade Guarani, existem ações relevantes e consolidadas da terapia ocupacional neste contexto. As ações técnicas exercidas ratificam a relevância do papel do terapeuta ocupacional nos contextos culturais e na esfera da etnicidade. Essas práticas, por conseguinte, são pertinentes para a produção de conhecimento e para a formação teórico-metodológica e profissional em terapia ocupacional social e contextos culturais. Destaca-se que procedimentos técnicos coerentes com as questões de etnicidade, numa relação conjunta e horizontal, articulados pela mediação cultural, podem fortalecer os fazeres humanos e as afirmações identitárias.
\end{abstract}

Palavras-chave: Terapia Ocupacional, Prática Profissional, Cultura, Grupos Étnicos, População Indígena.

\section{Forming insights: assessment of the occupational therapy practice in a cultural context from experience with indigenous people}

\begin{abstract}
This article is the result of a reflection process on the issue of occupational therapy and culture through analysis of practical experiences of a extension project. It aimed to increase knowledge and reflections of occupational therapy and its technical actions in cultural contexts from the perspective of ethnicity issues. It is a documental and qualitative research was aiming to report the experience of students and an occupational therapist, obtained through their written reports between 2012 and 2014. Data were analyzed using the categorizations proposed by Bardin. The categories of analysis found are related to technical activities in occupational therapy, namely: cultural and ethnic action. The results showed that, in the experiences with the Guarani community, there are already significant and consolidated actions of occupational therapy in cultural contexts. The technical actions already performed confirm the relevance of the occupational therapist role in the cultural context and in the ethnicity context. These practices are, in turn, relevant for the production of knowledge, the theoretical and methodological scope and professional training in social and cultural contexts of occupational therapy. It is emphasized that technical procedures coherent with the ethnicity issues in a joint relationship, articulated by cultural mediation, can strengthen human doings and identity claims.
\end{abstract}

Keywords: Occupational Therapy, Professional Practice, Culture, Ethnic Groups, Indigenous Population. 


\section{Introdução}

O presente artigo resulta de um processo de reflexão que o Núcleo UFES do projeto Metuia ${ }^{1}$ vem realizando acerca da temática terapia ocupacional e cultura. Este núcleo, criado no ano de 2014, pela articulação de três principais projetos de Extensão ${ }^{2}$ coordenados pelos docentes da área social do curso de terapia ocupacional, tem contribuído para a formação teórico-metodológica e profissional em terapia ocupacional social.

O projeto "Terapia Ocupacional e os jovens Guarani do Espírito Santo: diálogos e oficinas culturais" visa a criar intervençôes, em um cenário de conflitos interculturais, a partir da inserçáo dos estudantes de terapia ocupacional na aldeia Guarani Três Palmeiras, na cidade de Aracruz, localizada no litoral capixaba, distante $83 \mathrm{~km}$ da capital, Vitória.

Esse projeto foi pioneiro nas extensóes da terapia ocupacional social da Universidade Federal do Espírito Santo - UFES e teve início no ano de 2011, a partir de estudos sobre as necessidades dos jovens das aldeias Guarani. Suas açôes abrangem grande número de estudantes que circulam pelo projeto, tendo por diferencial o enfoque cultural.

Diante desse cenário, os debates em torno dos contextos culturais e terapia ocupacional foram se tornando frequentes ao grupo de docentes e extensionistas do projeto e de docentes de outras Universidades. No ano de 2013, a Universidade Federal do Espírito Santo, em parceria com a Câmera Técnica em Contextos Sociais do Crefito2, promoveu o I Encontro de Terapia Ocupacional e diversidade cultural na aldeia Guarani de Aracruz-ES.

Já no ano de 2014, a partir da proposiçáo do "plano de trabalho do estágio pós-doutoral" da terapeuta ocupacional Patrícia Dorneles, o projeto participou de uma das rodas de conversa ${ }^{3}$ sobre terapia ocupacional e cultura no cenário acadêmico e profissional brasileiro. Esse encontro visava à troca de experiências, à difusão e ao mapeamento de "[...] açóes e interfaces de terapeutas ocupacionais que atuam em diálogo com açôes e políticas da diversidade cultural [...]" (DORNELES, 2014).

Nessa perspectiva, o objetivo deste estudo é articular e aprofundar - através dos relatos de estudantes extensionistas e de uma técnica do projeto na aldeia - os conhecimentos teórico-metodológicos da terapia ocupacional em contextos culturais. Busca-se desvelar as questôes de etnicidade e cultura, e sua relação com as ações técnicas, do terapeuta ocupacional, realizadas junto ao povo Guarani.

Para fundamentar a análise dos dados e a discussão, optou-se por fazer um breve histórico da terapia ocupacional social e suas relaçóes com os contextos culturais, bem como do projeto de extensão e do povo Guarani.

\subsection{A constituição do campo social da terapia ocupacional e o caminhar para os contextos culturais}

$\mathrm{Na}$ constituição da terapia ocupacional, o início epistemológico da profissão, segundo Morrison, Olivares e Vidal (2011), se deu ao final do século XIX e se baseou em fundamentos teóricos do tratamento moral, da filosofia pragmática e do movimento de artes e ofícios, consolidando-se em um modelo chamado de Pré-paradigma da Ocupação. Nos anos seguintes, os terapeutas ocupacionais utilizaram a ocupação como agente de promoção, tratamento e restauração. Contudo, à luz do neopositivismo lógico, momento em que o conceito de ciência se reduz a variáveis e dicotomias, a profissão buscou sua legitimidade junto às ciências biomédicas, sob o Paradigma Mecanicista, baseado na dicotomia saúde-doença.

Já no período entre a modernidade e a pós-modernidade, os autores nos apontam que ocorreu a consolidação do Paradigma da Ocupação. Neste momento, retomaram-se os fundamentos iniciais da profissão, centrados no eixo da ocupação, e se iniciou o fortalecimento das Ciências da Ocupação, embora ainda se caracterizasse como um fenômeno de abordagem individual e subjetiva. Na atualidade, o chamado Paradigma Social da Ocupação já considera a ocupação como um fenômeno sistêmico, complexo, econômico, político, sanitário, cultural, social e coerente com a justiça e bem-estar das comunidades, e inserido em algo maior, que seria o Paradigma da Complexidade, fundamentado pelas teorias de Edgar Morin (1998). Nesse cenário, compreende-se a Terapia Ocupacional Social enquanto campo de atuação, pois:

La TO comunitária o la TO social, son ejemplares de este paradigma, las que se diferencian (cualitativamente) de las prácticas anteriores de la profesión y aparecen en la comunidad científica como reconocidas o como necesarias para la sociedad actual. Algo similar ocurre con "lo político" de la $\mathrm{TO}$, en donde se asume que el rol y ejercicio profesional conlleva decisiones políticas inherentes a los y las terapeutas ocupacionales, así como en las intervenciones se desarollan aspectos de ciudadanía centrados en los derechos humanos [...] (MORRISON; OLIVARES; VIDAL, 2011, p. 113). 
No Brasil, a Terapia Ocupacional Social se instituiu enquanto campo, no bojo das transformaçóes sociais ocorridas devido ao processo de redemocratizaçáo, iniciado no final de 1970. Alguns terapeutas ocupacionais, atentos aos movimentos sociais e imersos num processo de reflexáo acerca da realidade social e da sua prática profissional, notaram que suas açôes tinham um compromisso político e social, buscando, pois, "[...] participar em projetos de açóes sociais e em instituiçóes até então distantes de seus interesses [...]" (BARROS; GHIRARDI; LOPES, 2002, p. 97).

Os terapeutas ocupacionais passaram a debater não só a possibilidade de habitarem diferentes instituiçôes, como a lógica desses espaços ${ }^{4}$. Começaram a questionar os campos, o objeto e os métodos de atuação, culminando para uma discussáo de maior pertinência referente ao cerne da profissáo. Requerer-se-ia que a ação técnica ultrapassasse os espaços especializados e buscasse tecer açóes que levassem em consideraçáo as identidades singulares e coletivas, e que contemplasse a complexidade da vida em comunidade.

Desse modo, o campo social se estabeleceu com demandas e populaçóes específicas, com as quais a terapia ocupacional foi capaz de colaborar e contribuir com o arcabouço de conhecimento que detinha acerca da mediaçáo do fazer e do saber-fazer humano (BARROS, 2004). A intervenção do terapeuta ocupacional passou a constituir-se como

[...] espaços sociais de negociação cultural e relacional, de produção ou facilitação de participaçáo da pessoa na vida coletiva, na elaboração de projetos de vida e no sentimento de pertencimento e, náo podem ser compreendidos através de separaçóes e disjunçōes [...] (BARROS, 2004, p. 92)

Para tanto, foi preciso buscar novos referenciais teóricos, "[...] rever os conceitos de ocupação, de trabalho e de atividade [...]" (BARROS; GHIRARDI; LOPES, 2002, p. 100), e pensar no desenvolvimento de metodologias de abordagens que permitissem acompanhar os indivíduos e os coletivos em sua historicidade e seus contextos, bem como entender suas relaçôes socioculturais.

Nessa perspectiva, os conhecimentos socioantropológicos passaram a ser incorporados pelos terapeutas ocupacionais e o conceito de cidadania tornou-se o princípio orientador da práxis desses profissionais. Diante das ações profissionais, fez-se inegável a coexistência de diversidades múltiplas no território brasileiro, demandando que fossem pensadas formas de se trabalharem a multiculturalidade e as diferenças.
A partir desse contexto, a terapia ocupacional social passou a interagir e a usufruir de dois conceitos estimados pela antropologia: os conceitos de cultura e de alteridade, tomando-os junto ao conceito de cidadania como instrumentos potencializadores e articuladores de suas intervençôes (BARROS, 2004; BARROS; LOPES; GALHEIGO, 2007a).

A princípio, os terapeutas ocupacionais utilizaram o conceito de cultura ${ }^{5}$ para interpretar com mais clareza "os significados atribuídos às coisas e às relaçôes" que compunham o cotidiano dos indivíduos e grupos a quem acompanhavam. O intento era de que não só as diferenças fossem compreendidas, mas também que um meio de diálogo pudesse ser construído, de modo que os saberes se tornassem compartilhados e que os usuários dos serviços, na relação de alteridade com o profissional, vivenciassem de forma mais democrática a intervenção, com relaçóes horizontais, dialógicas e de exercício da cidadania (BARROS; LOPES; GALHEIGO, 2007a, p. 352).

No Brasil, de acordo com Fernandes (2010, p. 38), a cultura aparece nos escritos constitucionais primeiramente fazendo referência, a partir de 1934, à "[...] proteção das ciências, das artes e da cultura em geral [...]". Em 1988, "[...] a Constituiçâo fala pela primeira vez em direitos culturais, no artigo 215 , o qual estabelece os direitos culturais na categoria de direitos humanos fundamentais [...]", e pauta que, ao Estado, caberia garantir o integral exercício desses direitos. Gonh esclarece que, ao campo dos direitos culturais, cabe:

[...] temas, questôes e problemáticas relacionadas às múltiplas dimensóes do ser humano tais como gênero, raça, etnia, religião, faixas etárias, nacionalidades. Abrange também o produto e a obra produzida por esses seres humanos em suas relaçóes sociais [...]; expressóes artísticas, manifestações culturais e folclóricas locais, regionais e nacionais; práticas de ensino e aprendizagem; esporte e lazer. O campo dos direitos culturais penetra também no modo e estilo de vida cotidiana [...] (GONH, 2008 apud FERNANDES, 2010, p. 38).

Desse modo, o debate sobre cultura também esteve inscrito no processo de redemocratização do Brasil e colaborou para as mudanças sociais ocorridas. No que tange à terapia ocupacional e sua aproximação aos contextos culturais, Dorneles pontua, no site 'Terapia Ocupacional e Cultura', que:

A experiência da intersetorialidade vivida no processo de construção da terapia ocupacional no campo social nos anos 1990 potencializou 
a aproximação de uma prática profissional da área junto a ações culturais. Estas ações, geralmente associadas a projetos de oficinas de artes, encontravam-se inicialmente em contextos de programas localizados nas políticas de assistência social, onde a arte e a cultura eram inseridas na perspectiva do desenvolvimento social. Embora ainda de forma frágil, há uma aproximação de algumas iniciativas da terapia ocupacional no campo da arte e cultura identificada na pauta das políticas culturais. Cabe destacar aqui que, no mesmo período em que se questionavam as instituições totais, as políticas públicas de cultura também passavam por um processo de desinstitucionalização da arte, do artista e das suas instituiçóes culturais (DORNELES, 2014).

Alguns terapeutas ocupacionais já demonstraram a importância da questão cultural para a terapia ocupacional, como Brunello (1991); Barros, Ghirardi e Lopes (1999); Barbosa (2010); Dorneles (2011); Barros (2004); Barros, Almeida e Vecchia (2007); Barros, Lopes e Galheigo (2007b); Galvani e Barros (2010); Silva e Carraro (2014), e tantos outros estudos, bem como os que a consideram em suas práticas profissionais. Além disso:

Tornou-se imperativo para o terapeuta ocupacional desenvolver atividades culturalmente pertinentes, pois se trata de compreender como as atividades mais valorizadas são percebidas na comunidade e como estão articuladas aos símbolos chaves que formam as identidades. Exige-se, então, do terapeuta ocupacional a capacidade de constituir intervençóes coerentes com as culturas locais específicas, fato que determina uma ruptura com açóes moduladas por procedimentos técnicos pré-estabelecidos. O outro é noção (alteridade) relacional, construída no diálogo (BARROS; ALMEIDA; VECCHIA, 2007, p. 132).

Contudo, destaca-se os terapeutas ocupacionais já atuantes em contextos diversos, articulados também a diferentes grupos culturais e comunidades. Sendo que:

O terapeuta ocupacional, em diferentes contextos (MACEDO, 2010; COSTA, 2008; COSTA; FAGUNDES, 2010; REDE MOCAMBOS, 2008; PONTES, 2011; COSTA; ALVARENGA; ALVARENGA, 2007; FUNDAÇÃO..., 2004), tem sido um importante colaborador na discussão e na articulação de propostas que, produzidas no interior das próprias comunidades referidas, se constituem em estratégias de potencialização da ocupação (nos dois sentidos já apresentados) como direito social [...] (COSTA, 2012, p. 52).

É notável a importância dos fundamentos da terapia ocupacional social para a construção de açóes e conteúdos nos contextos culturais, dada a compreensão de que, no cenário brasileiro, coexistem

[...] identidades de matrizes várias (europeia, indígena, africana, asiática), com intensificação da questão das diferenças (culturais, de classe, gênero, idade e raça) e das desigualdades, que requerem novas formas de se trabalhar [...] (BARROS; ALMEIDA; VECCHIA, 2007, p. 129).

Todavia, necessita-se avançar no debate e nas construçóes acerca do papel do terapeuta ocupacional nos contextos culturais, a fim de que as práticas profissionais sejam coerentes e pertinentes às populaçóes que as demandam.

Posto isso, o presente estudo propóe incluir a dinâmica da etnicidade nos aportes teórico-metodológicos dos contextos culturais em terapia ocupacional, compreendendo que, quando se reporta às questóes de etnicidade, refere-se à existência de questóes intrínsecas e específicas que compóem essa esfera, na qual surgem fatores inerentes à organização social da diferença ${ }^{6}$. Sugere-se que a etnicidade

[...] refere-se aos aspectos das relaçóes entre grupos que consideram a si próprios como distintos. Do ponto de vista da interação, o processo de identificação étnica se constrói de modo contrastivo, isto é, pela "afirmação do nós diante dos outros" (CARDOSO DE OLIVEIRA, 1976, p. 5). Assim, a partir de Barth (1969), as diferenças culturais adquirem um elemento étnico náo como modo de vida exclusivo e tipicamente característico de um grupo, mas quando as diferenças culturais são percebidas como importantes e socialmente relevantes para os próprios atores sociais [...] (O'DWYER, 2005, p. 95).

\subsection{Contextualizando o campo de estudo: breve histórico ${ }^{7}$ do povo Guarani e do projeto de extensão em contextos culturais}

Os Guarani representam uma das maiores populaçóes indígenas encontradas no Brasil. Segundo IBGE (INSTITUTO..., 2010), no censo demográfico, encontraram-se autodeclarados mais de 67 mil Guarani no Brasil. Eles estão divididos em subgrupos: os Guarani-Ñandeva, os Guarani-Kayowá 
e os Guarani-Mbyá, que apresentam diferenças linguísticas, nas práticas rituais, nos costumes e na organização política e religiosa (INSTITUTO..., 2015).

Pensando-se na história dos Guarani no Espírito Santo, podemos relatar que, de acordo com Ciccarone (2001), os Guarani-Mbyá chegaram ao Espírito Santo em meados de 1960. Atualmente, se concentram em Caieiras Velhas, região de Aracruz. Contudo, sua longa trajetória fora motivada por inúmeras causas, como a revelação religiosa, os conflitos pela terra, os conflitos internos nas aldeias, o trabalho forçado nas fazendas, a morte de parentes e a exploraçáo para o turismo.

Segundo Pellon (2008), os Mbyá de Aracruz viveram, durante as quatro últimas décadas, sob forte confinamento territorial em uma regiáo onde se situam mais quatro aldeias Tupiniquim, três distritos urbanos, três rodovias estaduais e a antiga multinacional Aracruz Celulose - atualmente nomeada FIBRIA. Esta é a maior produtora de celulose branqueada do mundo e integra extensas áreas de monocultura de eucalipto a um complexo fabril, e um porto marítimo dedicado à exportação de seus produtos. Em 2007, conforme o autor, chegou ao fim uma disputa fundiária que ganhou visibilidade internacional pela ampla divulgaçáo na mídia de que os índios representavam um obstáculo ao desenvolvimento econômico regional.

O projeto de extensão "Terapia Ocupacional e os jovens Guarani do Espírito Santo: diálogos e oficinas culturais", iniciado em 2011, se situa no contexto apresentado, está intimamente ligado às necessidades dos jovens e se reforça pelo recorte étnico do subgrupo Guarani-Mbyá. A proposta visa a problematização de questôes identitárias, socialização e interação entre os jovens Guarani, Tupiniquim das aldeias de Aracruz e de outras comunidades Guarani. Para tanto, tem como base a realização de procedimentos, como grupos e oficinas de atividades, atividades comunitárias e acompanhamentos individuais junto às crianças e aos jovens.

Quanto aos instrumentos e recursos, têm se destacado o teatro, a dança, o desenho, os jogos, as reuniōes comunitárias, os mutirôes para a organização física do espaço territorial, além dos recursos multimeios e de materiais produzidos pelos próprios índios, como documentários, textos e blogs. Dessa forma, têm-se proporcionado espaços de discussóes sobre temáticas da juventude com recorte étnico e sobre processos de emancipação, cidadania e valorização cultural.
O intuito de trabalhar o recurso dos multimeios nas oficinas justifica-se pela possibilidade de manter o acesso à informação e às trocas de experiências com as mais diversas etnias, além de estas poderem produzir suas próprias críticas e análises sobre seus contextos. O contato constante na cidade com diferentes influências e diferentes diálogos interculturais não tem propiciado dinâmica étnica aos jovens, nem eco e voz para o aprofundamento de suas raízes e afirmaçóes identitárias.

Vale destacar que, embora o projeto esteja voltado, a princípio, aos jovens Guarani, nos anos de 2013 e 2014 houve uma aproximaçáo significativa por parte das crianças às atividades. Surgiram, assim, demandas deste público e açóes voltadas a ele por meio das oficinas de brincadeiras e jogos, que, enquanto recursos, objetivaram trabalhar a necessidade das crianças de experimentaçóes identitárias e de expressão cultural do cotidiano em comunidade, através da autoexpressão.

As oficinas culturais foram definidas mediante a pesquisa realizada junto aos jovens, em 2011, sendo que o objetivo principal dos primeiros encontros era conhecer os jovens da aldeia e as atividades que gostariam de realizar, além de motivaçóes pessoais e comunitárias. A partir daí, foram inúmeros encontros, que possibilitaram uma maior interação entre comunidade e universidade. Ademais, o projeto se tornou referência aos jovens quando necessitavam de acompanhamentos individuais em questôes pessoais, como matricular-se para exame de vestibular, escolha de cursos universitários, fluxos no mercado de trabalho, bem como demandas coletivas, como a realização de mutirôes, eventos e inscrição da comunidade no Projeto ProJovem do Ministério do Trabalho e Emprego ${ }^{8}$.

\section{Metodologia}

Trata-se de uma pesquisa documental, com o objetivo de aprofundar os conhecimentos da terapia ocupacional em contextos culturais. Conforme Silva et al. (2009), essa metodologia de pesquisa permite investigar uma dada realidade social a partir de documentos produzidos pela humanidade, os quais, na perspectiva de Bravo, são documentos as produçóes em que o homem mostra

[...] indícios de sua ação e que podem revelar suas ideias, opinióes e formas de atuar e viver. Nesta concepção é possível apontar vários tipos de documentos: os escritos; os numéricos ou estatísticos; os de reprodução de som e imagem; e os documentos-objeto 
[...] (BRAVO, 1991 apud SILVA et al., 2009, p. 4556).

A abordagem dos dados, por sua vez, foi qualitativa, caracterizada pela compreensáo da palavra que expressa a fala, cabendo ao pesquisador explorar e refletir as falas dos sujeitos participantes a fim de trazer à tona seus significados (LANDIM et al., 2006).

Para tanto, partiu-se do entendimento de que a atividade de extensão, segundo a ótica de Paulo Freire, pode - e deve - se inscrever para além do caráter assistencialista, exercendo um papel fundamental de comunicação entre Universidade e sociedade (RODRIGUES, 1999). Dessa forma, os projetos de extensão são passíveis de se desdobrarem em campo de pesquisa, desenvolvendo estudos que envolvam tanto a comunidade à qual se oferta as atividades extensionistas como os corpos docente, discente e técnico envolvidos no processo das práticas.

Nessa perspectiva, a participação dos estudantes no projeto diz respeito tanto a programação e efetivação das atividades extensionistas quanto ao registro das experiências e das açôes realizadas na aldeia Guarani, por meio de relatos escritos, fotografias, vídeos, divulgação em mídia, entre outros, contribuindo, pois, para a construção de um banco de dados próprio do Núcleo Metuia e, consequentemente, para a produção de pesquisas sobre o campo e as práticas de extensão.

O grupo de estudantes extensionistas sempre variou em número e momento de formação; inicialmente, eram três estudantes de quinto período, mas, com estratégias de divulgaçáo do projeto, passaram a ter envolvimento no projeto de oito a 20 estudantes, principalmente aqueles que estavam no quarto período, momento em que realizavam a disciplina de terapia ocupacional social. Também participaram estudantes de outros cursos, como ciências sociais, biologia, comunicação, direito e história. No entanto, para este estudo, a análise será realizada somente com relatos de estudantes e da técnica de terapia ocupacional.

Desse modo, a presente pesquisa usou como dados brutos os relatórios escritos dos participantes do projeto, a fim de obter o relato das experiências para análise. Vale ressaltar que, embora as experiências do projeto de extensão estejam ocorrendo desde 2011, os relatórios utilizados estáo compreendidos entre os anos de 2012 e 2014. Portanto, para este estudo, foram levados em consideração alguns relatos de experiência que se destacaram pela relevância para a discussão da atuação da terapia ocupacional nos contextos culturais junto aos povos indígenas.
Quanto ao tratamento e à análise dos dados qualitativos, ocorreram mediante a análise de conteúdo proposta por Bardin (2011), uma vez que esta possibilita ao pesquisador descobrir os sentidos das comunicaçôes, pois a presença ou a frequência destas desvelam significados pertinentes para se alcançar o objetivo proposto pela pesquisa. Os resultados brutos foram tratados no intento de serem validados para que os pesquisadores realizassem as inferências e interpretaçôes à luz das teorias inicialmente elegidas e chegassem às conclusôes.

As categorias de análise encontradas estão relacionadas à ação técnica em terapia ocupacional, sendo intituladas: ação cultural e ação étnica.

\section{Projeto de extensão em}

contextos culturais: reflexões
sobre a ação técnica do
terapeuta ocupacional com
povos indígenas

No atual cenário da legitimação dos campos de trabalho da terapia ocupacional, como fruto do movimento ativo e reflexivo dos terapeutas ocupacionais da área social para firmá-la como área de atuação legítima, foi aprovada a Resolução n.o 383, de 22 de dezembro de 2010, do Conselho Federal de Fisioterapia e Terapia Ocupacional (COFFITO, 2010).

Com o intuito de definir as "competências do terapeuta ocupacional nos Contextos Sociais" e oferecer "outras providências", a Resolução n. ${ }^{\circ} 383$, em dois de seus parágrafos aponta atribuiçôes do terapeuta ocupacional próprias ao Contexto Sociocultural:

[...] Art. $5^{\circ} \mathrm{O}$ terapeuta ocupacional, no âmbito de sua atuaçáo, realiza acompanhamento do indivíduo e sua família para conhecimento de sua história ocupacional e participativa na comunidade em que habita a fim de desenvolver estratégias de pertencimento sociocultural e econômico, adaptaçóes ambientais e urbanísticas, mobilidade, acessibilidade e outras tecnologias de suporte para inclusão sociocomunitária. [...] Art. $10^{\circ} \mathrm{O}$ terapeuta ocupacional, no âmbito de sua atuaçáo, trabalha campo social com pessoas, famílias ou grupos em situação de migração, deslocamento, asilo ou refúgio por meio de atividades como tecnologia de mediação sócio-ocupacional a fim de fortalecer e/ou de desenvolver redes de suporte e de trocas afetivas, econômicas e de informaçôes, desenvolvendo estratégias de pertencimento sociocultural e econômico, 
adaptações ambientais, organização da vida cotidiana, a construçáo de projetos de vida, acessibilidade e outras tecnologias de suporte para inclusão sociocomunitária e de favorecimento do diálogo intercultural (CONSELHO..., 2010, s/p.).

Nota-se, diante desses artigos, que a legitimação de um campo de atuação perpassa por diversas esferas que dizem respeito não só aos instrumentos ${ }^{9}$ e recursos utilizados nas práticas profissionais, mas também aos fundamentos das intervençóes técnicas, aos princípios articuladores das intervençóes e aos procedimentos técnicos realizados pelos terapeutas ocupacionais. Todos esses domínios epistemológicos constituem a base para que os terapeutas ocupacionais possam desenvolver suas intervençóes de forma mais próxima às realidades e aos contextos acompanhados.

Destaca-se que o campo epistemológico não se dá de forma desconexa, pois, contrariamente, suas esferas estão em constante diálogo e são interdependentes. Com isso, o presente estudo apresenta as reflexóes realizadas acerca dos fundamentos das intervençóes técnicas nos contextos culturais, isto é, das ações técnicas, entendidas como um conjunto de proposiçóes que norteiam as práticas para materializaçáo da intervenção. Tais fundamentos oferecem, na relação com a realidade, aqui cultural, elementos para se criarem alternativas de intervenção.

A partir dos resultados, ainda seráo citados brevemente, mas não de forma menos importante, alguns princípios articuladores, procedimentos e instrumentos de intervenção que se sobressaíram e perpassaram as açóes técnicas, contribuindo também para suas formulaçóes.

Assim, as duas categorias a seguir apresentadas, baseadas nas açôes culturais e étnicas, discorrem sobre as ações técnicas sob as quais a intervenção cultural, enquanto abordagem do terapeuta ocupacional, pode se fundamentar.

\subsection{Ação técnica do terapeuta ocupacional em contextos culturais: ação cultural}

De acordo com Geertz (1989), a cultura pode ser compreendida como uma teia de significados que grupos humanos estabelecem sobre as relaçóes entre si e com a natureza, sobre os modos de vida, sobre costumes, crenças e identidades. Em consonância, Sahlins (1997) apresenta a cultura como a capacidade singular da espécie humana de tanto ordenar e desordenar o mundo, em termos simbólicos, quanto nomear e distinguir a organização da "experiência humana" e da "ação humana" por meio de seus valores e significados. Barth (2005), por sua vez, ratifica tais entendimentos apontando que a cultura refere-se, portanto, às formas de aprendizado do homem por meio de suas experiências humanas $\mathrm{e}$ às produçóes que esse aprendizado gera.

Nessa perspectiva, entende-se ação cultural em terapia ocupacional como açóes pertinentes aos contextos culturais dos indivíduos, nas quais se busca compreender as formas de organização simbólica das experiências e ações humanas, e as formas de aprendizado dos grupos, bem como as construçôes das diferenças entre os grupos no que tange aos seus modos de vida e às suas relaçóes. Deste modo, a ação cultural também está relacionada às necessidades de grupos culturais quanto às expressóes artísticas, de linguagem, de questóes de gênero, de questóes etárias e de questóes econômicas.

A ação cultural demanda do terapeuta ocupacional a disponibilidade para o encontro com o outro, pois, na singularidade e no pertencimento, é possível identificar identidades e seus significados. Contudo, na prática extensionista, ao mesmo tempo em que os alunos se colocavam no processo do encontro com os jovens e crianças indígenas, também realizavam descobertas acerca de si mesmos, de seus limites e estranhamentos. A cada ação técnica e encontro, novas situaçóes se apresentavam e surpreendiam os estudantes, como decifrar símbolos de outra etnia, compreender suas cosmologias, ou até mesmo os novos significados apreendidos.

Outra troca muito bacana que ocorreu no dia, foi poder conhecer o grande artista Guarani, e as várias historias e significados de sua vida, seu povo suas obras em 3D, e o lindo significado de sua tatuagem, feita com cores naturais e espinho. $O$ simbolo dos guaranis, as pontas e suas representaçóes (pajé, esposa de pajé), os guerreiros, a floresta e no centro o significado do seu nome, que lhe foi passado em um ritual [...] (Extensionista $G$ ).

Nessa conjuntura, a alteridade - capacidade ímpar de reconhecer a condição humana do outro, considerando-se suas características próprias e distinçóes - exerceu o papel de princípio articulador, proporcionando a dialogia para que se identificassem as necessidades individuais e coletivas, bem como os estranhamentos.

Dessa forma, a partir das relaçóes de alteridade, é possível estabelecer o diálogo intercultural e, principalmente, a negociação cultural, estratégias imprescindíveis para a prática da ação cultural. Para a extensionista ' $D$ ', a negociação cultural é processual e, por meio dela, conseguiram estabelecer trocas 
de saberes. De acordo com a estudante, "apesar de resistentes no começo, depois os jovens interagiram e participaram, sugerindo novas ideias, o que nos proporcionou conhecer os seus gostos e pensar em possibilidades de atividades significativas para eles".

Com a convivência no cotidiano Guarani e a partir das açóes culturais realizadas pelo projeto, foi possível identificar as adaptaçôes, ressignificaçóes e transformaçóes dos fazeres. Em um relato, o estudante ' $E$ ' disse: "[...] o meu primeiro choque se deu ao me deparar com o uso da tecnologia (DVD, videogame, celular, internet) em uma comunidade que eu imaginava ser tradicional [...]".

Nota-se, porém, nas palavras do estudante, certo estranhamento diante da realidade devido ao estereótipo de imutabilidade tradicional e cultural que compóe o imaginário popular acerca dos povos tradicionais. A respeito dessa visão estereotipada, Costa (2012) destaca que é necessário ter a clareza de que as tradiçôes são mutáveis e que a possibilidade de mudança e desenvolvimento lhes são de direito, pois a cultura é um processo e náo uma condição estática no tempo e no espaço. Sem esse entendimento, certas culturas, principalmente de povos indígenas e comunidades tradicionais, por vezes, são transformadas em patrimônio cultural da humanidade. Isto ocasiona alienação e manutenção da desigualdade, mascarada sob o título de multiculturalismo, com a justificativa da preservaçáo de uma tradição, o que não é uma garantia de direito à diferença, mas sim de um processo de exclusão.

Assim, na ação cultural, busca-se não reduzir as diferenças culturais a traços fixos, constitutivos da natureza humana. Contrariamente, a compreensão das açóes dos sujeitos volta-se à sua própria forma de se inscrever nos espaços e nas relaçôes, conforme notamos no relato da aluna 'G':

Ficou designado a mim, juntamente com outras alunas, irmos para a cozinha e ajudar as mulheres da aldeia a cozinharem. [...] Foi ai que começou o meu processo de colocar a lentelos óculos do outro. As mulheres indígenas, pelo menos as da aldeia Três Palmeiras, diferentemente das mulheres não indias, ao cozinharem falam pouco, somente o necessário, mesmo quando estão em muitas. O momento da conversa acontece fora da cozinha enquanto fumam seus cachimbos e deixando os preparos no fogo, aparecendo de tempo em tempo para ver se tudo está indo bem. Quando a comida fica pronta, são elas quem preparam os pratos das demais pessoas da aldeia, entregando-os de forma que ninguém diferente precise entrar na cozinha, somente as crianças [...] (Extensionista G).

Em consonância, Hannerz (1997) aponta que tem se experimentado cada vez mais fluxos culturais polimorfos, nos quais se torna difícil identificar uma cultura como pertencente a uma localidade restrita, pois cultura não se trata apenas de uma herança imutável, mas sim de um processo que sofre transformaçóes a partir das experiências das pessoas, das quais elementos são subtraídos e adicionados antes de continuarem sendo transmitidas. As pessoas, como seres culturais, são moldadas por suas histórias, experiências, redes de relacionamentos e gostos, não havendo necessariamente uma identidade de grupo totalitária e sim ideias compartilhadas e descontinuidades.
Descobri através do diálogo com um jovem Guarani que a caça é utilizada na obtenção de alimentos. Porém, ela é realizada de forma equilibrada, respeitando as leis da natureza e as épocas propicias para caça de cada espécie. [...] O mesmo jovem nos levou à residência do Pajé, que construiu sua própria casa com bambus colbidos e cortados por ele mesmo. Diferente da minha cultura, o labor é valorizado e o tempo não é um inimigo. [...] Foi-nos explicado que existem os pajés responsáveis pela produção dos medicamentos, todos naturais, e outros responsáveis pela espiritualidade. Todas as noites os Guarani se reúnem na casa de reza para os ritos sagrados. Lá, recebem orientaçooes, curas e afastam os espiritos maus. O jovem possui uma longa trajetória nos esportes, pratica o futebol na aldeia todos os sábados, [...] eventualmente basquetebol e voleibol. Além desses esportes, mantém a tradição indigena através de oficinas semanais de arco e flecha, zarabatana e lança. São promovidas também oficinas de canto e danças tipicas da cultura Guarani [...] (Extensionista E).

Esse diálogo entre os extensionistas e o jovem exemplifica que ser Guarani não é necessariamente possuir uma cultura isolada. Em alguns momentos, cultivam-se alguns símbolos provindos dessa identidade étnica, dando continuidade cultural de sua tradição, mas estes símbolos não esgotam as ideias e habilidades que a pessoa adquire em suas trajetórias de vida (BARTH, 2005).

Nessa perspectiva, a açáo cultural torna-se pertinente nos contextos culturais, uma vez que se propóe a avançar na compreensão do conjunto de símbolos e suas interações, e da distribuição dos significados e das formas significativas, que propiciam as distinçóes entre os grupos, buscando possibilitar ao terapeuta ocupacional o reconhecimento do outro na sua condição de outro, desconstruindo o estereótipo de que a cultura é estática. O foco da ação cultural é, pois, as relaçôes de alteridade, complementadas pelo diálogo intercultural e pela negociação cultural, contribuindo para a sensibilização 
do olhar e das práticas do terapeuta ocupacional, de modo a levá-lo a pensar nas variadas esferas que compóem os contextos culturais.

\subsection{Ação técnica do terapeuta ocupacional em contextos culturais: ação étnica}

Parte-se das conceituaçôes sobre cultura à luz de Geertz (1989), Sahlins (1997) e Barth (2005), para a apreensão do conceito de etnicidade (BARTH, 2005). Etnicidade diz respeito à maneira como os grupos étnicos se organizam socialmente por meio de seu pertencimento étnico, sobre como suas relaçôes e formas de interações são constituídas, mas não com o olhar voltado à localização fixa da sua cultura, e sim aos seus fluxos e contrafluxos, às suas produções e reproduçóes.

Dessa forma, considera-se que, embora as ações culturais possam ser realizadas com os distintos grupos pela terapia ocupacional nos contextos culturais, na dinâmica da organização social dos grupos étnicos, propóe-se também a ação étnica - ações específicas relacionadas aos grupos étnicos e à dinâmica da etnicidade -, uma vez que, no processo de organização social e de pertencimento étnico, poderão surgir problemas de várias ordens, relacionados às relaçôes de poder entre culturas, como dominaçáo, preconceito, racismo, hierarquia das experiências e do aprendizado, da própria organizaçáo espacial/territorial, dos aspectos ecológicos ou mesmo no campo das negociaçóes em fronteiras étnicas mais porosas ou fluidas.

Compreende-se que uma ação não exclui a outra, mas é necessária a distinção, pois a cultural se faz no contexto mais global de interaçóes e as questóes étnicas, em contextos específicos e determinados pelos próprios grupos étnicos. Nessa perspectiva, entendem-se por ação étnica, as ações realizadas junto a grupos étnicos - grupos que apresentam particularidades em sua organização social, territorial e linguagem e que, a partir de suas identidades étnicas, realizam interaçôes, negociações, autodistinções - tanto para a mediaçáo de conflitos culturais quanto para ressignificar suas identidades em fronteiras étnicas.

No projeto de extensão, é latente vivenciar experiências em que se observam as demandas e necessidades surgidas no processo de organização e diferenciação social dos Guarani. Dentre as vivências, destaca-se uma experiência ocorrida em 2014, quando o projeto esteve envolvido na mediaçáo do diálogo intercultural para a implantação do Programa ProJovem Trabalhador - programa do
Ministério do Trabalho e Emprego desenvolvido em parceria com Municípios e Governos de Estado -, que tem o intuito de preparar o jovem para o mercado de trabalho e como forma alternativa de renda. Podiam participar jovens com idades entre 18 e 29 anos, que estivessem desempregados e que fossem membros de famílias com renda per capita de até um salário mínimo.

A princípio, pôde-se considerar que a implementação do ProJovem nas aldeias Guarani fazia jus à Política Nacional para o Desenvolvimento Sustentável de Povos e Comunidades Tradicionais (PNPCT), instituída em 2007, a partir do Decreto 6.040 do Governo Federal, que prevê a garantia da inclusáo dos Povos e Comunidades Tradicionais nos programas, serviços e equipamentos das demais políticas, considerando-se características locais, respeitando a cultura e seu direito à diversidade (cultural, social, produtiva, ambiental e relacional). Contudo, foi possível perceber o não reconhecimento à diversidade cultural brasileira, como no relato de uma extensionista:

[...] surgiu a oportunidade de participarmos de uma reuniāo com os representantes das aldeias (guarani e tupiniquim) para esclarecimentos do objetivo do programa projovem trabalhador. [...] cada aldeia iria ter um curso diferente, visto que relataram dificuldades entre locomoção entre aldeias (já que o programa não contempla vale transporte) e a comunicação era um complicador. [...] O curso escolhido pelo cacique Guarani a ser ofertado foi o de madeira e móveis, sendo que no minimo seriam necessárias 20 pessoas e no máximo 30. Durante o curso com duração de seis meses, todos os inscritos receberão uma bolsa auxilio, lanche, material didático, e camisa. Epara que o mesmo pudesse ser realizado deveriam preencher uma fich a cadastral e anexar a xerox dos documentos de identificação básicas, e tudo isso dentro de um curto periodo de tempo. [...] surgem algumas questöes, como por exemplo, o lanche a ser oferecido. Trata-se de um lanche industrializado, do qual o cacique não gostou [...]. Outra questão a ser apontada foi quanto aos materiais disponíveis, que não são voltados para uma demanda e realidade daquela aldeia, mas que de certo modo me pareceram bastante flexiveis quanto as possibilidades de algumas adaptaçóes para aquele contexto, e finalmente a questão de como iriam preencher aquele papel tão quadradinho e tirar xerox de documentos de um dia para o outro praticamente? Senti-me profundamente tocada naquele momento e percebi nitidamente na feição do representante da aldeia, aquela cara de interrogação. Percebi que ali poderíamos articular e ajudar a resolver esse problema. Nesse momento senti que podia falar, apesar de não estar 
tão segura quanto à possibilidade de tentarmos articular juntamente com o projeto essa mediação, mas arrisquei a tentativa e acho que foi acatado por todos os envolvidos. Fizemos então todos os contatos necessários e combinamos de retornar [...] (Extensionista G).

Nota-se que o Programa ProJovem Trabalhador não levou em consideração as características locais, como preconiza a PNPCT, como, por exemplo, a idade compreendida como juventude para os Guarani, sua relação com o trabalho e também as constituições familiares. Além disso, a ementa do curso (de madeira e móveis) de preparação ao trabalho que o ProJovem oferecia e o lanche que disponibilizavam aos participantes não condiziam com as práticas culturais Guarani. Da mesma forma, os Guarani expressaram encontrar dificuldades para o preenchimento do cadastro, que exigiam a manipulação e o entendimento de uma linguagem, e o manejo de equipamentos aos quais não estavam acostumados. Conforme aponta Costa (2012), o que se tem na prática são políticas públicas sociais normatizadas em um Brasil considerado uniforme e que, muitas vezes, desconsidera as especificidades culturais.

Nesse sentido, destaca-se, ainda, no relato da extensionista 'G', como proposição para situaçóes de conflitos interculturais, a articulação da ação étnica à dinâmica da etnicidade, no intuito de, metodologicamente, à luz de Barth (2005), iniciar as açóes com os grupos conflitantes por pontos e questóes comuns, expandi-los progressivamente mediante a exploração de questóes compartilhadas e, desta forma, superar as fronteiras étnicas, com marcos em diferenças, focando na continuidade da diversidade cultural.

Logo, se fez pertinente a mediação cultural durante a reunião de planejamento, enquanto estratégia da ação étnica do terapeuta ocupacional, uma vez que esta auxiliou no agenciamento do diálogo intercultural e interétnico, de modo a promover a troca de informaçóes entre os envolvidos (a comunidade Guarani, a comunidade Tupiniquim, os professores das comunidades e os agentes do programa ProJovem), para que o programa pudesse ser implementado na aldeia.

Outra questão importante aparece no protagonismo dos Guarani, que atentamente criticaram o formato do curso e, com apoio da terapia ocupacional, também negociaram adaptaçóes e reformulações da estrutura do curso. Os Tupiniquim não apresentaram demandas, afirmando que conseguiriam se adaptar ao que estava sendo solicitado. A partir deste dia, o vínculo entre os extensionistas e a população das aldeias se estreitou ainda mais, promovendo diálogos que os fizessem expressar as expectativas e perspectivas que tinham com relação ao programa ProJovem Trabalhador, e permitindo que os auxiliássemos nesse processo.

O nosso grupo de estagiários e de extensionistas participou da inscrição dos jovens das Comunidades Guarani de Aracruz no Projovem Trabalhador. Foi um momento riquissimo, em que a terapia ocupacional pode mediar as relaçóes e os contratos interculturais a fim de que a própria comunidade pudesse assumir o protagonismo no exercício da cidadania. Por conta desse processo, tivemos a oportunidade de vivenciar as relaçôes, as atividades e os papeis cotidianos de um dia da semana da comunidade (tendo em vista que geralmente participamos das atividades que acontecem aos sábados - dia da semana mais voltado às atividades de lazer). Ao mesmo tempo, no laboratório de informática do Centro Cultural da aldeia Três Palmeiras, explicávamos aos jovens Guarani como a ficha do Projovem precisava ser preenchida. Juntos xerocávamos os documentos e ímos conversando sobre os dados cadastrais, o português era traduzido para o guarani e o guarani dava acesso ao entendimento do projeto. Não havia sobreposiçóes, mas a igualdade na diferença! Sentimos na pele a dinamicidade do processo de (re) construção cultural vivido pelos Guarani e algumas de suas ressonâncias. Ao final do dia os jovens Guarani, além das fichas preenchidas assumiram o lugar que lhes é de direito e numa ação emancipatória, à sua maneira, eles mesmo estavam administrando as inscrições. Se pudéssemos resumir o dia de hoje em palavras seriam estas: Respeito, Gratidão, Ação Comunitária, Diálogo Intercultural, Solidariedade, que juntas dizem um tanto dessa relação de Alteridade que buscamos construir, que não existe pautada na instantaneidade, mas sim num contínuo e profundo processo de afetação mútua [...] (Técnica voluntária).

Percebe-se, no relato da 'técnica voluntária', que a intervenção da terapia ocupacional, através da ação étnica, proporcionou a negociação entre os envolvidos na inscrição ProJovem e os jovens, resultando em diálogo intercultural e interétnico, e no equacionamento das diferenças. Assim, através da troca de saberes, foi possível que eles próprios construíssem seus protagonismos, contribuindo para o processo de emancipaçáo social e do exercício de cidadania cultural.

No contexto social e cultural, a ação do terapeuta ocupacional é tomada como estratégia de mediação de conflito, a fim de que, por meio da ação social, cultural e étnica, promova rearranjos e equacionamentos, uma vez que a 
[...] noção de conflito emerge da interaçáo e suscita divergências, antagonismos tanto de interesse como de percepção. Há conflitos nas relaçóes entre indivíduos e grupos, e conflitos inerentes à organização social, política e econômica [...] (BARROS; LOPES; GALHEIGO, 2007a, p. 351).

Nas atividades comunitárias e na oficina de atividades, as negociaçóes interculturais possibilitaram conhecer melhor o território da aldeia e o cotidiano dos Guarani e dos vizinhos Tupiniquim, suas identidades étnicas e possíveis demandas para a ação étnica, como a criação de um espaço para turismo e divulgação da cultura local, e a problematizaçáo do uso de drogas.

Propomos também aos jovens que nos apresentassem a aldeia, os locais que eles gostavam de ir, o que gostavam de fazer. Chegamos a conhecer a aldeia temática, local a margem do rio Piraqueaçu, onde já foi filmado um curta-metragem sobre a cultura Guarani, é bastante agradável e dentro da perspectiva da comunidade de se transformar num local para realização de visitas $e$ atividades tradicionais [...] (Extensionista A). Como o nosso tempo é diferente do tempo deles não tivemos como contestar ou propor mudanças naquela rotina. Todavia, vislumbramos a oportunidade de conversar com um indigena tupiniquim, que estava presente nesse dia para uma reunião, e então as demandas foram surgindo como, por exemplo, a questão da mediação de conflitos entre a cultura indigena dos tupiniquins e as drogas [...] (Extensionista G).

Através dos relatos das experiências dos estudantes, observou-se que estes apresentaram olhares críticos para a ação neste campo e proporcionaram reflexóes relevantes para as ações técnicas, para a formação, articulando referenciais teóricos e metodológicos pertinentes aos contextos culturais em terapia ocupacional junto aos povos indígenas.

Mesmo assim, percebe-se que a atuação nos contextos culturais ainda demanda novos aportes teóricos e metodológicos que necessitam de aprofundamento e análises, embora verifique-se que açôes já aconteçam e que estas demonstram a relevância do papel do terapeuta ocupacional nestes contextos.

\section{Considerações finais}

O percurso histórico da terapia ocupacional no campo social e no contexto cultural discorrido nos instiga a pensar sobre o debate acerca do campo epistemológico da profissão e a propor contribuiçôes neste campo, que está em constante construção e reformulação.

No contexto cultural apresentado, nota-se que foi a partir da vivência dos modos de ser e de fazer do outro, do compartilhamento do cotidiano e de suas tramas com esse outro, que as intervençôes aconteceram.

Dentre os procedimentos realizados, a oficina de atividades, as atividades comunitárias e os acompanhamentos se desenvolveram como um espaço de criação e construção, em que os estudantes exercitaram relaçôes de alteridade, a compreensão da ação técnica em contextos culturais e das atividades enquanto mediação cultural para a concretizaçáo de objetivos, como a afirmação identitária.

Ainda viabilizou-se o desenvolvimento de novas metodologias para que as práticas terapêuticas ocupacionais continuem a buscar leituras coerentes com as realidades socioculturais, com os sujeitos e grupos os quais acompanham, ratificando seu compromisso ético e sua ação cultural e étnica.

Assim, evidencia-se que as açôes técnicas e os procedimentos realizados pelo terapeuta ocupacional nos contextos culturais, quando coerentes com as questôes de etnicidade, numa relação conjunta e horizontal, e articulados pela mediaçáo cultural, podem fortalecer os fazeres humanos.

Entendemos, pois, que a prática profissional do terapeuta ocupacional deve, de forma qualitativa e com compromisso ético, político e técnico, responder às demandas dos povos indígenas e, conjuntamente, criar estratégias e açōes efetivas neste contexto. Para isso, entende-se que novos estudos e inter-relaçóes teórico-práticas devam acontecer desde os primeiros anos de formação do terapeuta ocupacional, estimulando o aprendizado para novos olhares.

\section{Referências}

BARBOSA, N. D. Fendas na cultura: a produçáo de tecnologias de participaçáo socioculturais em terapia ocupacional. 2010. 233 f. Dissertaçáo (Mestrado em Ciências) - Universidade de São Paulo, São Paulo, 2010.

BARDIN, L. Análise de conteúdo. São Paulo: Almedina Brasil, 2011.

BARROS, D. D. Terapia ocupacional social: o caminho se faz ao caminhar. Revista de Terapia Ocupacional da Universidade de São Paulo, São Paulo, v. 15, n. 3, p. 90-97, 2004.

BARROS, D. D.; ALMEIDA, M. C.; VECCHIA, T. C. Terapia ocupacional social: diversidade, cultura e saber técnico. Revista de Terapia Ocupacional da Universidade de São Paulo, São Paulo, v. 18, n. 3, p. 128-134, 2007. 
BARROS, D. D.; GHIRARDI, M. I. G.; LOPES, R. E. Terapia ocupacional e sociedade. Revista de Terapia Ocupacional da Universidade de São Paulo, São Paulo, v. 2, n. 3, p. 69-74, 1999.

BARROS, D. D.; GHIRARDI, M. I. G.; LOPES, R. E. Terapia ocupacional social. Revista de Terapia Ocupacional da Universidade de São Paulo, São Paulo, v. 13, n. 3, p. 95-103, 2002.

BARROS, D. D.; LOPES, R. E.; GALHEIGO, S. M. Novos espaços, novos sujeitos: a terapia ocupacional no trabalho territorial e comunitário. In: CAVALCANTI, A.; GALVÃO, C. (Org.). Terapia ocupacional: fundamentação e prática. Rio de Janeiro: Guanabara Koogan, 2007b. p. 354-363.

BARROS, D. D.; LOPES, R. E.; GALHEIGO, S. M. Terapia ocupacional social: concepçóes e perspectivas. In: CAVALCANTI, A.; GALVÃO, C. (Org.). Terapia ocupacional: fundamentaçáo e prática. Rio de Janeiro: Guanabara Koogan, 2007a. p. 347-353.

BARTH, F. Etnicidade e o conceito de cultura. Revista Antropolítica, Niterói, n. 19, p. 15-30, 2005.

BASAGLIA, F.; BASAGLIA, F. O. Los crimenes de la paz: investigación sobre los intelectuales y los técnicos como servidores de la opresión. México: Siglo XXI, 1977.

BASAGLIA, F.; BASAGLIA, F. O. O homem no pelourinho. São Paulo: Instituto de Psiquiatria Social, 1979.

BRASIL. Ministério do Trabalho e Emprego - MTE. ProJovem Trabalhador. Brasília, 2014. Disponível em: $<$ http://www3.mte.gov.br/politicas_juventude/projovem_default.asp >. Acesso em: 23 abr. 2014.

BRUNELLO, M. I. B. Reflexóes sobre a influência do fator cultural no processo de atendimento de Terapia Ocupacional. Revista de Terapia Ocupacional da Universidade de São Paulo, Sáo Paulo, v. 2, n. 1, p. 30-33, 1991.

CICCARONE, C. Drama e sensibilidade: migração, xamanismo e mulheres mbya guarani. 2001. $382 \mathrm{f}$. Tese (Doutorado em Ciências Sociais) - Pontifícia Universidade Católica de São Paulo, São Paulo, 2001.

CONSELHO FEDERAL DE FISIOTERAPIA E TERAPIA OCUPACIONAL - COFFITO. Resolução $\mathrm{n}^{\circ} .383$, de 22 de dezembro de 2010. Define as competências do Terapeuta Ocupacional nos Contextos Sociais e dá outras providências. Diário Oficial [da] Repuiblica Federativa do Brasil, Poder Executivo, Brasília, DF, 25 dez. 2010. Seção 1, p. 80. Disponível em: <http://www.coffito.org.br/site/index.php/home/ resolucoes-coffito/462-resolucao-n-383-2010-define-as-competencias-do-terapeuta-ocupacional-nos-contextos-sociais-e-da-outras-providencias.html>. Acesso em: 22 set. 2014

COSTA, S. M. Terapia Ocupacional Social: dilemas e possibilidades da atuaçáo junto a povos e comunidades tradicionais. Cadernos de Terapia Ocupacional da UFSCar, São Carlos, v. 20, n. 1, p. 43-54, 2012. http:// dx.doi.org/10.4322/cto.2012.005.
DORNELES, P. Território e territorialidades na Rede Cultura Viva da Regiáo Sul: Programa Cultura Viva. In: BARBOSA, F.; CALABRE, L. (Org.). Pontos de cultura: olhares sobre o Programa Cultura Viva. Brasília: Ipea, 2011. p. 229-245.

DORNELES, P. Roda de conversa: terapia ocupacional e cultura: contextos e possibilidades. São Carlos: UFSCar, 2014. Disponível em: <https://sites.google.com/site/ terapiaocupacionalecultura/do-projeto $>$. Acesso em: 20 set. 2014.

FERNANDES, N. M. A cultura como direito: reflexôes acerca da cidadania cultural. Latitude, Maceió, v. 4, n. 1, p. 33-53, 2010.

GALVANI, D.; BARROS, D. D. Pedro e seus circuitos na cidade de São Paulo: notas sobre uma experiência em situação de rua. Interface, Botucatu, v. 14, n. 35, p. 767-779, 2010. http://dx.doi.org/10.1590/S141432832010005000022 .

GEERTZ, C. A interpretação das culturas. Rio de Janeiro: Zahar, 1989.

GOFFMAN, E. Prisóes, manicômios e conventos. São Paulo: Perspectiva, 1974.

HANNERZ, U. Fluxos, fronteiras, híbridos: palavras-chave da antropologia transnacional. Revista Mana, Rio de Janeiro, v. 3, n. 1, p. 7-39, 1997.

INSTITUTO BRASILEIRO DE GEOGRAFIA E ESTATÍSTICA - IBGE. O Brasil indígena: censo demográfico 2010. Rio de Janeiro, 2010. Disponível em: <http:// indigenas.ibge.gov.br/images/pdf/indigenas/folder_indigenas_web.pdf $>$. Acesso em: 7 abr. 2015.

INSTITUTO SÓCIO-AMBIENTAL - ISA. Povos Indigenas no Brasil. São Paulo, 2015. Disponível em: <http:// www.socioambiental.org/pt-br>. Acesso em: 7 abr. 2015.

LANDIM, F. L. P. et al. Uma reflexão sobre as abordagens em pesquisa com ênfase na integração qualitativo-quantitativo. Revista Brasileira em Promoção da Saúde, Fortaleza, v. 19, n. 1, p. 53-58, 2006. http://dx.doi. org/10.5020/18061230.2006.p53.

MORIN, E. Ciência com consciência. Rio de Janeiro: Bertrand Brasil, 1998. $<$ /bok $>$

MORRISON, R.; OLIVARES, D.; VIDAL, D. La filosofía de la ocupación humana y el paradigma social de la ocupación: algunas reflexiones y propuestas sobre espistemologías actuales em terapia ocupacional y ciências de la ocupación. Revista Chilena de Terapia Ocupacional, Santiago, v. 11, n. 2, p. 102-119, 2011.

O'DWYER, E. C. Os quilombos e as fronteiras da antropologia. Revista Antropolítica, Niterói, n. 19, p. 91111, 2005.

PELLON, L. H. C. Tensóes interculturais e os impactos no processo saúde-doença na população Guarani Mbyá do município de Aracruz, Espirito Santo. 2008. 243 f. Dissertação (Mestrado em Enfermagem) - Universidade Federal do Estado do Rio de Janeiro, Rio de Janeiro, 2008. 
RODRIGUES, M. M. Universidade, extensão e mudanças sociais. Revista em Extensão, Uberlândia, v. 1, n. 1, p. 41-51, 1999.

SAHLINS, M. O. "Pessimismo sentimental" e a experiência etnográfica: por que a cultura não é um "objeto" em via de extinção (parte I e II). Revista Mana, Rio de Janeiro, v. 3, n. 2, p. 103-150, 1997.

SILVA, C. R.; CARRARO, L. E. A arte da sobrevivência ou sobre a vivência da arte. Interface, Botucatu, v. 18, n.
48, p. 237-243, 2014. http://dx.doi.org/10.1590/180757622013.0890

SILVA, L. R. C. et al. Pesquisa documental: alternativa investigativa na formaçáo docente. In: CONGRESSO NACIONAL DE EDUCAÇÁO - EDUCERE, 9., 2009, Curitiba. Anais... Curitiba: PUCPR. Disponível em: <http://www.pucpr.br/eventos/educere/educere2009/anais/pdf/3124_1712.pdf>. Acesso em: 23 abr. 2015.

\section{Contribuição dos Autores}

Maria Daniela Macedo e Amabile Neves foram responsáveis pela coleta de dados, reflexão, análise e redação das ideias. Giovanna Bardi e Gustavo Monzeli foram responsáveis pela revisão das ideias e Vinícius Mota colaborou com a coleta de dados do artigo. Todos os autores aprovaram a versão final do texto.

\section{Notas}

${ }^{1}$ O Projeto Metuia se constituiu em 1998 em três universidades paulistas (USP, UFSCar e PUC-São Paulo), como um grupo interinstitucional com açóes no âmbito do ensino, da pesquisa e da extensão em defesa da cidadania das populações em processos de ruptura das redes sociais de suporte (BARROS; LOPES; GALHEIGO, 2007b). Atualmente, quatro núcleos estão em atividade: o núcleo da Universidade de São Paulo (USP), o núcleo da Universidade Federal de São Carlos (UFSCar), o núcleo da Universidade Federal de São Paulo (UNIFESP) e, mais recentemente, o núcleo da Universidade Federal do Espírito Santo (UFES).

${ }^{2}$ Compõem o Programa de Extensão Metuia - UFES, os seguintes projetos: "Terapia Ocupacional e os jovens Guarani do Espírito Santo: diálogos e oficinas culturais", "Terapia ocupacional social, juventudes e intervençóes urbanas e culturais” e "Grupo de estudos sobre a terapia ocupacional social: produção de conhecimento e formação profissional" sob coordenação de Maria Daniela Corrêa de Macedo, Giovanna Bardi e Gustavo Artur Monzeli.

${ }^{3}$ A atividade Roda de Conversa - Terapia Ocupacional e Cultura: Contextos e Possibilidades faz parte da proposta de pesquisa, intitulada "Por uma terapia ocupacional na gestão e nas ações de políticas culturais", que integra o plano de trabalho do estágio pós-doutoral de Patrícia Dorneles, o qual realizou-se junto à Linha de Pesquisa "Redes de Suporte e Vulnerabilidade" do Programa de Pós-Graduação em Terapia Ocupacional da Universidade Federal de São Carlos (PPGTO/UFSCar), sob supervisão de Roseli Esquerdo Lopes e Denise Dias Barros.

${ }^{4}$ Tais reflexôes foram influenciadas por teóricos como Goffman (1974), que discorria sobre as instituiçóes destinadas aos sujeitos marginalizados como instituiçóes totais, e Basaglia e Basaglia (1977, 1979), que as consideravam instituiçôes de violência (BARROS; GHIRARDI; LOPES, 2002).

${ }^{5}$ A cultura pode ser entendida como um conjunto de símbolos que interagem uns com os outros e entrelaçados constroem uma trama de significados (GEERTZ, 1989).

${ }^{6}$ Tais fatores estão relacionados às distinções entre os diversos grupos étnicos, que apresentarão diferenças em seus modos de vida, linguagem, cosmovisôes, formas de enfrentamentos e interaçóes, e se utilizarão destas identidades étnicas para a negociação e a reivindicação nas tensões e conflitos, como no caso territorial.

7 Cuidados éticos: O projeto conta com a anuência das lideranças das aldeias Guarani, oralmente e por escrito, para realização do projeto de extensão com jovens e crianças da comunidade, como estudos correlatos. A coordenadora acredita que o percurso construído através da realização de outros projetos nas aldeias Guarani, tanto de Aracruz quanto de Ubatuba, favoreceu sua autorização, pois a relação mútua de respeito já foi estabelecida com a comunidade Guarani.

${ }^{8}$ O ProJovem Trabalhador é um programa do Ministério do Trabalho e Emprego, que tem por objetivos principais "preparar o jovem para o mercado de trabalho e para ocupaçôes alternativas geradoras de renda". De acordo com a legislação do programa, podem participar dele "[...] os jovens desempregados com idades entre 18 e 29 anos, e que sejam membros de famílias com renda per capita de até meio salário mínimo [...]” (BRASIL, 2014).

${ }^{9}$ Entende-se que, para o terapeuta ocupacional do campo social, as atividades podem ser os instrumentos de intervenção. Estas são consideradas como o meio que viabiliza o contato, as açôes técnicas e os procedimentos profissionais nos campos e contextos de atuação. 